\title{
Andrea Mazzucchi, Un episodio della fortuna di Dante in Francia nel primo Ottocento: Les Proscrits di Honoré de Balzac
}

\section{Marco Stupazzoni}

\section{(2) OpenEdition}

\section{Journals}

\section{Edizione digitale}

URL: https://journals.openedition.org/studifrancesi/26506

DOI: $10.4000 /$ studifrancesi.26506

ISSN: 2421-5856

\section{Editore}

Rosenberg \& Sellier

\section{Edizione cartacea}

Data di pubblicazione: 1 avril 2007

Paginazione: 193

ISSN: 0039-2944

\section{Notizia bibliografica digitale}

Marco Stupazzoni, «Andrea Mazzucchi, Un episodio della fortuna di Dante in Francia nel primo Ottocento: Les Proscrits di Honoré de Balzac», Studi Francesi [Online], 151 (LI | I) | 2007, online dal 30 novembre 2015, consultato il 23 novembre 2021. URL: http://journals.openedition.org/studifrancesi/ 26506 ; DOI: https://doi.org/10.4000/studifrancesi.26506

Questo documento è stato generato automaticamente il 23 novembre 2021.

\section{cc) (†) $\odot$}

Studi Francesi è distribuita con Licenza Creative Commons Attribuzione - Non commerciale - Non opere derivate 4.0 Internazionale. 


\title{
Andrea Mazzucchi, Un episodio della fortuna di Dante in Francia nel primo Ottocento: Les Proscrits di Honoré de Balzac
}

\author{
Marco Stupazzoni
}

\section{NOTIZIA}

ANDREA MAZZUCCHI, Un episodio della fortuna di Dante in Francia nel primo Ottocento: Les Proscrits di Honoré de Balzac, in «Rivista di studi danteschi», anno III, fascicolo 2, luglio-dicembre 2003, pp. 468-480.

1 Particolarmente significativo per lo studio del mito di Dante in Francia nella prima metà dell'Ottocento è il romanzo filosofico Les Proscrits, pubblicato nel maggio 1831 ne «La Revue de Paris» e assunto successivamente (nel 1835) come peristilio del Livre mystique.

Dopo aver ricostruito la genesi del testo balzachiano, A. Mazzucchi affronta la delicata questione dei legami tra questo racconto e l'opera dantesca sotto una duplice prospettiva di lettura e di interpretazione: la prima, legata al motivo dell'esilio; la seconda, che «insiste invece sul carattere visionario ed esoterico della costruzione dantesca e sulle aperture mistiche presenti nella Commedia» (p. 474). La forza suggestiva esercitata da Dante su Balzac fu senza dubbio assai relevante: all'interno de Les Proscrits, lo scrittore francese «assimila la propria figura di interprete del pensiero di Swedenborg a quella di Dante» (p. 476). La ricezione in chiave ermetica della Commedia da parte di Balzac non fornisce tuttavia «chiavi particolarmente efficaci per la decifrazione dell'opera dantesca» (p.480): in ogni caso, l'assunzione della Divina Commedia in chiave mistica consente di «comprendere meglio la centralità del versante visionario e cosmico» della poetica balzachiana, dove l'analisi scientifica degli ambienti 
si combina con l'esigenza «quasi mistica di unità e armonia fra il mondo delle cose e quello dello spirito» (ibid.).

3 Una versione più breve e leggermente diversa di questo studio è apparsa, con il titolo Dante e Balzac, come Postfazione a H. de Balzac, I Proscritti (a cura di D. De Agostini, Roma, Salerno, 2003), di cui abbiamo avuto modo di occuparci in una delle precedenti rassegne. 